\title{
STUDY OF THE INFLUENCE OF DIFFERENT FACTORS ON TUMOR GROWTH ON A MODEL OF TRANSPLANTED EHRLICH'S MAMMARY GLAND ADENOCARCINOMA
}

\begin{abstract}
Savluchinskaya L.A., Ryzhova N.I., Deryagina V.P., Krivosheeva L.V., Khitrovo I.A. N.N. Blokhin National Medical Research Centre of Oncology, Ministry of Health of Russia, Moscow,e-mail: blood-research@yandex.ru

When conducting preclinical studies, it is necessary to use appropriate experimental models, which can further increase the effectiveness of anticancer therapy. The review showed the relevance of using Ehrlich's mammary gland adenocarcinoma (EAC) model for this purpose, represented by two strains (subcutaneous and ascites). In this model, a large number of substances have been successfully tested and their potential antitumor effect has been identified. The use of EAC has been expanded to include the study of agents such as tumor necrosis factor, as well as nanoparticles as targeted drugs. This model was used to study the unstructured protein apoptin of the chicken anemia virus (ApoA-1), which is capable of causing the death of tumor cells. Molecular mechanisms of carcinogenic action, including expression, angiogenesis and apoptosis in tumors, were studied using the example of the investigated factors tested on the EAC. The cell cycle and the role of macrophages in the tumor growth and inflammation have been investigated under the influence of potential anticancer agents. The review provides examples of the use of the EAC model in testing natural drugs that help overcome the toxicity and drug resistance of chemotherapeutic agents. The successful use of EAC has been shown in the study of various types of anticancer therapy (photodynamic, radiation, magnetic).
\end{abstract}

Keywords: Ehrlich's mammary gland adenocarcinoma, tumor growth, chemical and physical factors

Over the past decade, thanks to the success of fundamental and experimental sciences, data have been obtained that concretize and expand the understanding of oncopathogenesis. Advances in molecular biology have made it possible to deepen the understanding of the mechanisms of malignant transformation and metastasis, to identify and study potential targets for the action of pathogenetic drugs [1].

At the same time, increasing the effectiveness of chemotherapeutic treatment continues to be an urgent task. The potential therapeutic potential of a number of known pharmacological agents and new chemical compounds for the prevention and treatment of malignant tumors remains unclear. Thus, there is a need to search and use models that can most fully predict the clinical response when testing compounds under study. Such models should have the necessary potential not only to confirm cytotoxic activity, but also to obtain broader information about the mechanisms of antitumor action (including molecular ones), safety assessment, dose level and regimen, as well as the effectiveness of combinations of test compounds.

One of the approaches is the use of transplanted tumors as such models, which are still actively used to identify antitumor compounds. Information about the study of the interaction of the model with the compounds tested on it can contribute to obtaining new data not only on the properties of the tested agents, but also allows one to evaluate the biological characteristics of the experimental models used. The use of tumor strains transplanted into mice has a number of advantages: they are highly reproducible, can be stored for a long time, are easily transplanted to animals, and at the same time retain their initial histopathological characteristics. Ehrlich's mammary gland adenocarcinoma (EAC) is one such model.

According to the histological structure, it is a spontaneous undifferentiated adenocarcinoma of the mammary gland of a mouse, usually used as an experimental tumor by subcutaneous transplantation of tumor tissue into mice. It lends itself well to transplantation, multiplies rapidly, and is $100 \%$ malignant $[2,3]$. The model has proven itself well in the development of antitumor agents, as well as for obtaining the necessary information to understand the mechanisms of the inhibitory effect on tumor growth The use of this sensitive model made it possible to test on it a large number of different compounds with potential antitumor properties in order to obtain new information on the possible mechanisms of their inhibitory action on tumor growth. The results of studying the molecular mechanisms underlying the inhibitory action of the compounds are analyzed, and a search is made for possible therapeutic targets that can be used in subsequent chemotherapeutic treatment. The results of studies carried out on the EAC model and summarized in this review will allow a deeper assessment of the prospects for its preclinical use. First of all, due to the possibilities of studying antitumor mechanisms, the action of which is carried out by influencing the main processes of carcinogenesis, suppressing cell proliferation, stimulating apoptosis in transformed cells, as well as by increasing antitumor immunity.

\section{Chemical factors}

Improving the effectiveness of chemotherapeutic treatment continues to be an urgent 
task of oncopharmacology. The use of molecular hybridization of anticancer compounds allows the development of new drugs that can demonstrate better affinity for tumor cells and less severe side effects.

Acridine derivatives have attracted the attention of researchers because they have antitumor, antibacterial and antiviral properties. The resulting hybrid thiophene-acridine compound was tested in an EAC model and showed a significant reduction in tumor volume and cell viability. As a result, the compound was characterized as possessing potential antitumor properties, the cytotoxicity of which may be associated with the action of nitric oxide (NO) [4].

Another new compound, spiroacridine (at doses of $12.5,25$ or $50 \mathrm{mg} / \mathrm{kg}$ given intravenously), after seven days of treatment showed inhibitory effects on EAC growth, cell cycle, angiogenesis, and inflammation. The compound actively reduced the total number of viable cancer cells and the density of peritumoral microvessels, and also caused an increase in the G1 subpeak and the level of the Th1 cytokine profile. The antitumor effect of the drug can be explained by the modulating effect of the immune system on the Th1 cytokine profile and a decrease in the process of angiogenesis in the tumor [5].

The Ehrlich ascites carcinoma model has been successfully used to study the antitumor activity of a new analog of amsacrine $\mathrm{N}^{\prime}$ - (2-chloro-6-methoxyacridin-9-yl) -2-cyano-3- (4-dimethylaminophenyl) acryloidrazide (ACS-AZ10). It should be noted that amsacrine has pronounced side effects, including those caused by the development of resistance and low bioavailability. The new analogue amsacrine (ACS-AZ10) demonstrated greater antitumor activity compared to amsarkin due to a significant decrease in tumor mass and volume, viability of tumor cells and their total number. The arrest of the cell cycle and a decrease in the density of microvessels were also noted, which indicates its antiangiogenic effect [6].

A study [7] used EAC cells to induce subcutaneous tumors in $129 / \mathrm{SvJ}$ mice to study the effect of tumor on cardiac muscle function. EAC mice exhibited a significant decrease in left ventricular wall thickness, decreased ejection fraction, and severe muscle atrophy. In this model, the key signaling molecule mTOR, which is responsible for maintaining cell growth and autophagy, was suppressed. The same mechanism was observed in cancer patients in the course of tumor growth. Increased expression of transcription factors TFEB and
FoxO3a, which are involved in the regulation of the activation of genes for muscle atrophy, genes for lysosomal biogenesis, and genes for autophagy, was observed in the heart muscle of mice with tumors.

Thus, the authors showed that Ehrlich's subcutaneous adenocarcinoma causes cardiomyopathy in mice, which is associated with atrophy, fibrosis, and dysfunction of the heart; similar changes in the cardiovascular system are observed in cancer patients. It is expected that this model can be successfully used to identify potential therapeutic targets in the treatment of heart failure in patients with cancer and during chemotherapy.

Treatment of cancer patients with cytostatics leads to their pronounced toxic effect on healthy tissues. In an experiment carried out in mice, the possibility of using mTOR rapamycin (RAP) as an inhibitor was shown, which can reduce the adverse effects of paclitaxel on normal crypts of the jejunum in the presence of transplanted EAC [8].

As an experimental model, Ehrlich's mammary gland adenocarcinoma was used to study tumor necrosis factor (TNF-alpha) [9]. A new approach has been proposed to enhance the antitumor activity of TNF-alpha by extracorporeal removal of soluble receptors. The authors believe that such an increase in endogenous TNF-alpha activity can provide increased death of tumor cells without concomitant systemic toxicity and be one of the approaches to cancer treatment [10].

Lewis lung carcinoma and Ehrlich's mammary gland adenocarcinoma were used to study a composite preparation containing TNF-alpha and hematoporphyrin derivatives (PGP). The data obtained indicate that the complex drug was characterized by increased antitumor activity in comparison with its individual components. It inhibited both the primary tumor node and the metastatic process. The complex drug (TNF-alpha + PGP) is less toxic than the isolated form of TNF-alpha [11].

\section{Nanoparticles and other factors}

The drugs developed on the basis of nanoparticles are effective, provide minor side effects and have a targeted effect on tumor cells. The most commonly used materials for the preparation of nanoparticle carriers are dendrimers, polymers, liposomes, micelles, inorganic, organic nanoparticles. For example, anti-Mir-191 (Mir-191 - oncogenic microRNA expressed in breast cancer), loaded onto the liposomal complex of stearylamine, significantlyincreased the sensitivity of breast cancer 
cells to chemotherapy compared to drugs such as doxorubicin or cisplatin, if they were used in a free state [12].

On the transplanted EAC, studies were carried out using a complex lipid preparation based on the micellar form of cisplatin and a nanoferromagnet. An inhibitory effect on tumor growth and an insignificant toxic effect at the cellular and tissue levels were revealed. The use of this model made it possible to explain the mechanism of the inhibitory action of the drug due to the activity of connective tissue cells, as a result of which the tumor node was replaced by $60 \%$ with connective tissue cells [13]. The use of such composite drugs in clinical practice confirmed the observations noted in the experiments. Such drugs were characterized by a reduced toxic effect and increased prolonged antitumor action, with targeted delivery to target organs [14].

The results obtained on another experimental model, Guerin's carcinoma, also indicate that cisplatin in liposomal form has a higher specificity of antitumor action than the free form of cisplatin, both in susceptible and resistant animals with carcinoma in relation to cisplatin [15]. Lipid platinum chloride nanoparticles (LPC NPs) encapsulated with cisplatin have also shown promising anticancer effects in models of melanoma, bladder and liver cancer [16].

To determine the genotoxic and cytotoxic effects of AgNP in mice with EAC, various concentrations of $\operatorname{AgNP}(6,24$, and $48 \mathrm{mg} /$ $\mathrm{kg}$ ) were used, which were administered intraperitoneally (IP) and intratumoral (IT) methods. It has been shown that AgNP significantly increases (0.5-5 times) the level of malondialdehyde (MDA) and reduces the activity (32-64\%) of superoxide dismutase (SOD). In addition, AgNP caused a 2-3 fold increase in comet parameters (comet analysis), such as the percentage of tail DNA. Under the action of AgNPs, the tumor volume decreased by about $31-95 \%$ compared to the control. The results obtained showed that AgNPs have cytotoxic and genotoxic effects against Ehrlich's tumors. This confirms the antitumor properties of AgNPs [17].

Nanobiotechnology is a new alternative method for the synthesis of biocompatible nanoparticles. Phycobiliprotein was used in [18] for the synthesis of silver nanoparticles. In order to optimize the synthesis, phycoerythrin was used, extracted from the cyanobacteria Nostoc carneum using FCCD (centrally centered composite design). To characterize the synthesized AgNPs, they were studied and shown that it has a cytotoxic effect on normal cell cultures and human breast cancer cells. More informative results were shown using Ehrlich's ascites carcinoma (EAC). It was concluded that the phycoerythrin protein has the ability to synthesize AgNPs, which have antibacterial, antihemolytic, cytotoxic activity in vitro and in vivo. It was previously reported that AgNP had anticancer efficacy against Ehrlich carcinoma in mice due to its potential oxidative damage effect, evidenced by increased levels of malondialdehyde (MDA) and $\mathrm{H}_{2} \mathrm{O}_{2}$ in solid tumor tissue, indicating lipid peroxidation and free radical production in the tumor and induction of apoptosis through activation of caspases [19].

Thus, modern methods for the synthesis of nanoparticles and advances in nanotechnology have created the prerequisites for their biological and medical applications. The results, received on the ACE model, showed that nanoparticles can change the functional activity of not only normal, but also transformed cells due to transmembrane transport into the cell. Also the possibility of their use for targeting angiogenesis in various types of cancer, as well as for remodeling the tumor microenvironment in order to improve cancer immunotherapy has been shown. The transplanted EAC strain turned out to be a convenient model for experimental evaluation of new dosage forms - fluorescent nanoparticles and their ability to bind to tumor cells. The use of the methods of luminescence microscopy and spectroscopy made it possible to establish that the synthesized nanoparticles of rare-earth elements (spindle-shaped, spherical and rod-shaped) have an antitumor effect in vivo. The mechanism of realization of the antitumor effect in vivo also depended on the concentration of nanoparticles. It was shown that spindle-like nanoparticles at a concentration of $0.87 \mathrm{~g} / \mathrm{L}$ maximally inhibited the development of the tumor process, while in vitro, only spherical and spindle-shaped ones were able to distinguish between cancer stem cells [20].

One of the main aspects of modern oncology is the targeted transport of drugs to target tumor cells, which reduces the dose load without losing effectiveness. Ehrlich's ascites carcinoma was used to study the antitumor activity and safety of a new targeted drug, dactinomycin. The target for the action of the drug vector protein was the alpha-fetoprotein (AFP) receptor, and a recombinant glycoprotein was used as the vector. The advantage of targeting the drug to alpha-fetoprotein was that AFP receptors are found only in tumor cells, and they are absent in normal cells. Thus, the study carried 
out on this model confirmed the possibility of using this drug for targeted drug delivery to tumor tissue, which led to a significant decrease in the effective dose and toxicity [21].

The development of targeted drugs, including those using transgenes, is a priority in the treatment of cancer patients. The Ehrlich ascites carcinoma model made it possible to study the possibility of cell transfection using the lipofectamine 2000 protein, which is represented by apoptin (ApoA-1) and a transfection reagent. The authors showed the possibility of transfection and high cytolytic activity of apoptin in relation to the process of apoptosis of tumor cells. The use of the EAC model for these purposes was carried out for the first time. The creation of artificial liposomes containing high density lipoproteins (HDL) and their protein component ApoA-1 as a method for promising drug delivery is of undoubted interest [22].

\section{Macrophages and intracellular calcium}

The spectra of intracellular proteins of tumor-associated macrophages and peritoneal macrophages of healthy mice differ in the content of apolipoprotein (APO-E), as shown by the example of Ehrlich's mammary gland adenocarcinoma. This model has also been used to study the role of macrophages in the regulation of protein biosynthesis in normal and tumor cells under the action of high density lipoproteins (HDL) and cortisol. The results obtained showed that APO-E can play the role of negative feedback in the dynamics of the mechanism of protein biosynthesis in tumor cells [23].

The data obtained by the authors were confirmed by other works in which the participation of macrophages in tumor progression was studied. Studies have shown that the effect of macrophages on tumor growth may be determined by their ability to produce ROS, NOradicals, and a number of cytokines.

In experiments on mice with subcutaneous EAC transplantation, we studied the features of NO synthase expression depending on the growth rate of EAC. Immunohistochemical determination of enzymes was performed in tumors with different growth rates. It was shown that iNOS expression was detected in tumors with a higher growth rate at each growth period. More pronounced tumor progression was accompanied by an increase in the expression of both iNOS and eNOS. In tumors with a slower growth rate, iNOS expression was practically not detected. Expression of NO synthase depends on many factors, including an increased load of NO on tumor cells and phenotypic characteristics of target cells [24].
The regulation of tumor growth by macrophages is usually considered from two points of view - inhibitory and stimulating activity. APO-E can be one of the factors in the implementation of the antitumor effect. It follows from the literature that APO-E can suppress cell proliferation in various tissues, including tumor ones. It is also able to reduce gene expression through the $\beta$-catenin Wnt-signaling pathway, the activation of which plays an important role in carcinogenesis. Thus, depending on the implementation of the synthesis activation program, cell proliferation can be suppressed, or HDL and steroid hormones can be absorbed with the formation of a biologically active complex that enhances protein biosynthesis in tumor cells and APO-E secretion [25].

Intracellular calcium $\left(\mathrm{Ca}_{+}+\right)$is a mediator that regulates proliferation, differentiation and apoptosis in tumor cells. In addition to it, ROS and $\mathrm{pH}$ are involved in these processes. These factors $\left(\mathrm{CA}_{2}+, \mathrm{ROS}, \mathrm{pH}\right)$ are interrelated. The study of inhibition of proliferation processes is important for the study of the mechanisms of carcinogenesis and cancer prevention. For this purpose, the EAC ascites model was used, which is a rapidly multiplying population of cells and has receptors on the cell surface capable of regulating intracellular transport and the concentration of calcium ions $\mathrm{Ca}_{2}+[26,27]$.

The results obtained for the first time on the EAC model show that the dynamics of the content of $\mathrm{Ca}$ cations in ascites cells depends on the presence of reactive oxygen species. The amount of $\mathrm{Ca}$ cations depends on the phase of tumor growth, and their supply is carried out by calcium cations from different sources intracellular depots or extracellular space. A relationship was also found between intracellular signaling parameters such as $\mathrm{Ca}_{2}^{+}$, NAD (P) $\mathrm{H}$ and $\mathrm{pH}$. The authors conclude that the data obtained may indicate that during chemotherapy treatment, depending on the stage of tumor growth, instead of the cytotoxic effect, hyperproliferation may develop, aggravating the course of the oncological process [28, 29].

\section{Natural compounds}

The effect of herbal biologics with the potential to increase the effectiveness of anticancer therapy has also been studied in the EAC model. A significant amount of data has been obtained on the use of these drugs as chemotherapy modifiers [30].

This model made it possible to identify a number of substances with antioxidant, antimutagenic and antiangiogenic properties. These properties of the studied drugs were explained 
by the presence of certain compounds, such as natural polysaccharides, polyprenols (PP), fullerenols and aconites. Their action increased antitumor resistance. An increase in the induction of interferon (IFN) in the blood serum of animals with Ehrlich's mammary gland adenocarcinoma was revealed in animal experiments when studying polyprenol (a preparation obtained from the needles of the common spruce Picea abies (L.) Karst). Combined therapy with polyprenol and cyclophosphamide (CF) in the EAC model increased the lifespan of mice by $50 \%$ compared to the control and by $25 \%$ compared with the use of $\mathrm{CF}$ and reduced the toxic effect of the cytostatic without reducing its antitumor activity [31].

An aqueous suspension of Shiitaki mushrooms (Lentinus edodes) was studied on a transplanted EAC model. It was shown that the main component of the suspension, the polysaccharide lentinan, inhibiting tumor growth by $42-53 \%(p<0.05)$, activated nonspecific antitumor protection by stimulating the functional activity of peritoneal macrophages [32].

The development of anticancer drugs of plant origin is actively used at the present time, therefore, experimental studies aimed at assessing their biological, cytotoxic and antitumor activity are of great interest for researchers. Various models are used for these purposes, including the Ehrlich's mammary gland adenocarcinoma model (EAC).

Extracts from leaves, rhizomes and other parts of medicinal plants widely used in folk medicine, have shown pronounced antitumor activity against adenocarcinoma cells [33, 34]. The extracts had an inhibitory effect on EAC, significantly reducing tumor volume. When exposed to human cell cultures (cell lines of the mammary gland, liver and larynx), they caused an antiproliferative effect. In addition, in an experiment on mice with tumors, a decrease in the level of malondialdehyde (MDA) and an increase in the levels of superoxide dismutase and catalase in the liver tissue were observed under the influence of the studied natural plant products $[35,36]$.

Piperine is an amide alkaloid that has antitumor activity, but is highly toxic. The antitumor activity of a modified analogue of pipirin (pipranate $\mathrm{N}$ ) was studied after intraperitoneal and intravenous administration on Ehrlich carcinoma cells [37].

The study showed a decrease in the viability of tumor cells and the density of peritumoral microvessels; in addition, an increase in the level of the cytokine profile of Th1 helper T-lymphocytes, the content of reactive oxygen species and the production of nitric oxide was observed. Thus, the piperine analog studied in this model showed low toxicity, and its antitumor effect included modulation of the immune system to the Th1 cytotoxic profile. A similar effect on enhancing the antitumor effect was obtained by combining natural polysaccharides (pectins, chitosans) with cyclophosphamide (CP) [38].

The antitumor effect of the combination of fucoidans from the sulfated polysaccharide family with cycrophosphamide (CF) was shown in the EAC model. The inhibition of vascular development in the tumor and the antimetastatic effect of fucoidan were noted. In addition, anticoagulant, antithrombotic, antiviral and anti-inflammatory activity of the drug was observed in mice with tumors, and a decrease in the fixation of Helicobacter pylori on the gastric mucosa was noted [39].

In combination with $\mathrm{CF}$, the antitumor activity of the components of the polyphenolic complex of the herb Zostera marina, studied in prophylactic and therapeutic modes, has been shown [40]. Tincture of Aconite soongaricum showed the presence of antitumor and antimetastatic activity in the study on the experimental EAC model. The authors believe that with further improvement, its use may be useful in clinical practice [41].

The immunomodulatory properties of BioBran's arabinoxylan, derived from rice bran extract, were investigated in Ehrlich's mammary gland adenocarcinoma. It has been shown that the mechanism of its antitumor action is associated with the ability to influence such parameters as apoptosis, tumor necrosis factor alpha, gamma-interferons, immunosuppressive cytokine (interleukin-10) [42].

According to the results of a study [43], a modified drug BioBran / MGN-3 can complement cancer chemotherapy. The data obtained on the EAC model indicate the possibility of their further study in clinical practice as potential candidates for improving the quality of life of cancer patients.

\section{Physical factors}

In clinical practice, research is being actively carried out on methods of treatment using radiation and photodynamic therapy (PDT) and magnetic fields. The mechanisms of their effect on a wide range of tumors are being studied. Transplantable Ehrlich's mammary gland adenocarcinoma has proven successful for this type of experimental study. This model was used to study the process of the effect of PTD on the dynamics of tumor damage. It has 
been shown that when the tumor is exposed to the following changes occur in sequence: microcirculation disturbance, necrotic changes, hypoxia. All this took place against the background of the formation of scar tissue [44].

When carrying out chemotherapeutic treatment, patients often develop resistance to the drugs used. To prevent such phenomena, it is necessary to study dose-dependent effects, including with the involvement of experimental studies. Analysis of literature sources showed that such studies were successfully performed on transplanted tumors (for example, EAC). In experiments on $\mathrm{F}_{1}\left(\mathrm{NEAxC}_{57} \mathrm{BL} / 6\right)$ mice, which were transplanted with Ehrlich ascites carcinoma cells, a model was developed to study the effect of radiation exposure on antitumor resistance [45].

Post-radiation injuries are common in patients with malignant neoplasms who have received effective radiation therapy [46]. Therefore, there is a need for techniques that can prevent the adverse effects of radiation. An eNOS inhibitor was used that significantly reduced radiation damage to the skin in animals with Ehrlich's mammary gland adenocarcinoma. The effectiveness of radiation therapy has not decreased [47].

Another study examined the effects of different modes of exposure to electromagnetic radiation on animals with solid adenocarcinoma. A pronounced dependence of the effect on the dose of exposure and the possibility of obtaining a persistent antitumor effect are shown. It was concluded that the mechanisms of radiation antitumor action may be associated with a change in the immune status of the organism [48].

At present, the phenomenon of the antitumor effect of weak magnetic fields and their mechanism continues to be studied. The combined effect of constant and alternating lowfrequency magnetic field mechanisms has been studied in Ehrlich ascites carcinoma cells. It has been shown that the effect of magnetic fields of different frequencies affects the processes of apoptosis and necrosis, as well as the flutter of the plasma membrane and the production of nitric oxide [49].

The production of nitric oxide (NO) plays an important role in the effect of magnetic fields on tumor growth. From the literature data, it follows that under the influence of $\mathrm{NO}$, the expression of the heat shock proteins Hsp90, which provides antioxidant protection, as well as the nuclear protein P53, increases. In this case, there is an active expression of Bcl-2 proteins, which determine the cytotoxic activity of macrophages. Under the action of magnetic fields on animals with tumors, the survival period of experimental animals increases, which may be associated with the effect on cells at an early stage of apoptosis. At the same time, it was found that an increase in the amount of NO, which is produced by tumor cells, can stimulate tumor growth and thus suppress the activity of intratumoral T-lymphocytes, which is an unfavorable factor [50].

\section{Conclusion}

Thus, the review summarizes data based on numerous studies confirming the feasibility of using the model Ehrlich's mammary gland adenocarcinoma for the following purposes:

- possibility of studying the molecular mechanisms of inhibition of tumor growth was shown using the examples of the tested compounds. This model allows one to identify the mechanisms of the therapeutic effects of the compounds, which are mediated by inhibiting cell proliferation and angiogenesis, inducing apoptosis, increasing the level of P53 protein, suppressing the nuclear factor kappaB, decreasing the expression of genes for oxidative stress and decreasing the expression of EGFR;

- study of the antitumor activity of new chemotherapeutic drugs and / or herbal drugs, allows to identify with their help antitumor, antioxidant, antiangiogenic and antimutagenic properties of the substances under study. Allows you to assess their potential as new candidates for cancer treatment or as modifiers of the antitumor effect in order to increase the effectiveness of chemotherapeutic treatment and reduce the toxic effect of cytostatics in an experimental study;

- this model can be used in the study of targeted drugs, enhanced by the action of a transgene, which increases the possibility of targeted delivery to tumor tissue and significantly enhances the therapeutic effect of chemotherapy;

- with the use of EAC, the presence of cytotoxic, genotoxic and antioxidant properties of nanoparticles was shown and their directed transport to tumor cells was studied. The possibilities of using nanoparticles for targeting angiogenesis were investigated and determined, the relationship between the shape and size of nanoparticles and the ability of transmembrane penetration into tumor cells have been shown. The data obtained on the EAC model can supplement clinical and experimental studies for the development of effective tactics for the treatment of tumor diseases; 
- the role of macrophages in the regulation of tumor growth in the EAC model can be considered both in terms of inhibitory and stimulating activity;

- the subcutaneous Ehrlich's mammary gland adenocarcinoma can be used to study tumor cardiomyopathy due to the similarity of phenotypic features in the heart of mice and in cancer patients and the mechanisms of damage to the heart muscle due to the suppression of mTOR, a key signaling molecule. The resulting model can be used to identify potential therapeutic targets that may be present in cancer patients at risk of developing cardiomyopathy and in the presence of cardiac side effects during chemotherapy;

- The Ehrlich's mammary gland adenocarcinoma model can be used to study the effect of PDT on a tumor. This allows you to study the processes of damage to tumor tissue, microcirculation disorders and the formation of scar tissue;

- certain modes of exposure to radiation can be worked out on the EAS model, which makes it possible to study the dose-dependent effect of magnetic fields on tumor growth;

- experimental data obtained on this model using physical factors of influence may contribute to their wider use in the treatment of tumors.

\section{References}

1. Anfimov P.M. Targeted sequencing and peripheral monitoring in oncology // Materials of the $2^{\text {nd }}$ All-Russian conference on molecular oncology (in Rus). Advances in Mol Oncol. 2016. Vol. 4(3). P 13.; URL: http://www.tnimc.ru/nauka/uchastie-vkonferentsiyakh/russian-conference/6-8-dekabrya-2016-g-iivserossiyskaya-konferentsiya-po-molekulyarnoy-onkolo.

2. Larionov L.F. Himioterapiya zlokachestvennyh opuhole (in Rus). M. Medicina.: 1962. 463 p.

3. Ozaslan M, Karagos I.D., Kils I.H. and Guldur M.E. Erlich ascites carcinoma // Apr J Biotech. 2011. Vol.10 (13). P. 2375-2378.

4. Thaís Lisboa, Daiana Silva, Sâmia Duarte, Rafael Ferreira, CamylaAndrade, Ana Luiza Lopes, Juliana Ribeiro, Davi Farias Ricardo Moura, Malu Reis, Karina Medeiros, Hemerson Magalhães, Marianna Sobral// Toxicity and Antitumor Activity of a Thiophene-Acridine Hybrid// Molecules. 2019. Vol. 25 (1). 64. DOI: 10.3390/molecules25010064.

5. Daiana K Frade Silva, Sâmia S Duarte, Thaís M H Lisboa, Rafael C Ferreira, Ana Luíza de O Lopes, Deyse C M Carvalho, Sandra Rodrigues-Mascarenhas, Patricia Mirella da Silva, Miguel A S Pinheiro Segundo, Ricardo O de Moura, Karina C P Medeiros, Marianna V Sobral. Antitumor effect of a novel Spiro-Acridine compound is associated with up-regulation of Th1-type responses and antiangiogenic action // Molecules. 2019. Vol. 25(1). 29. DOI: 10.3390/molecules25010029.

6. Vivianne Mendes Mangueira, Tatianne Mota Batista, Monalisa Taveira Brito Tatyanna Kelvia Gomes de Sousa Ryldene Marques Duarte da Cruz, Renata Albuquerque de Abrantes, Robson Cavalcanti Veras, Isac Almeida de Medeiros, Karina Karla de Paula Medeiros, Ana Ligia da Costa Pereira, Vanessa de Lima Serafim, Ricardo Olímpio de Moura, Marianna Vieira Sobral. A new acridine derivative induces cell cycle arrest and antiangiogenic effect on Ehrlich ascites carcinoma model // Biomed Pharmacother. 2017. Vol. 10. P. 253-261. DOI: 10.1016/j.biopha.2017.03.049.

7. Sneha Mishra, Ankit Kumar Tamta, Mohsen Sarikhani, Perumal Arumugam Desingu, Shruti M Kizkekra, An- wit Shriniwas Pandit, Shweta Kumar, Danish Khan, Sathees C Raghavan, Nagalingam R Sundaresan. Subcutaneous Ehrlich ascites carcinoma mice model for studying cancer-induced cardiomyopathy // Sci Rep. 2018. Vol. 8(1). 5599. DOI: 10.1038/ s41598-018-23669-9.

8. Yurova M.N., Tyndyk M.L., Gubareva E.A. Study of the combined action of paclitaxel and rapamycin on the model of Ehrlich's transferable tumor // Modern approaches to the development of antitumor drugs: Materials of the $4^{\text {th }}$ All-Russian conference on molecular oncology (Moscow, 17-19 december 2018). Advances in Mol Oncol. (in Rus.). 2018. Vol. 5(4). P. 84.

9. Farma JM, Puhlmann M and Soriana PA. Direct evidence for rapid and selective induction of tumor neovascular permeability by tumor necrosis factor and moved deliberative colloidal gold, bound tumor necrosis factor // Int J Cancer. 2007. Vol. 120 (11). P. 2474-2480.

10. Steven F Josephs, Thomas E Ichim, Stephen M Prince, Santosh Kesari, Francesco M Marincola Anton Rolando Escobedo, Amir Jafri. Unleashing endogenous TNF-alpha as a cancer immunotherapeutic // J Transl Med. 2018. Vol. 16(1). 242. DOI: 10.1186/s12967-018-1611-7.

11. Sysoeva G.M., Danilenko E.D., Gamaley S.G., Bateneva A.V., Romanov V.P., Masycheva V.I. Anti-tumor activity of composite agent comprising tumor necrosis factor alpha with hematoporphyrin derivatives // Siberian Journal of Oncology. (in Rus.). 2010. Vol. 6. P. 36-41

12. Shivani Sharma, Vinoth Rajendran, Ritu Kulshreshtha, Prahlad C Ghosh. Enhanced efficacy of anti-miR-191 delivery through stearylamine liposome formulation for the treatment of breast cancer cells // Int J Pharm. 2017. Vol. 530 (1-2). P. 387400. DOI: 10.1016/j.ijpharm.2017.07.079.

13. Antipov S.A., Fedushchak T.A., Kokorev O.V., Gereng E.A., Dambaev G.S., Ermakov A.E., Uymin M.A., Khlusov I.A. Antitumor in vitro and in vivo effects of lipid composites of cisplatin and ferromagnetic nanoparticles capsulated by carbonic coating // Bulletin of Siberian Medicine (in Rus.). 2010. Vol. 1. P. 9-16. DOI: org/10.20538/1682-0363-2010-9-16.

14. Ivonin A.G., Pimenov E.V., Oborin V.A., Dervishov D.A., Kopylov S.N. Directed drug transport: Current state of the issue and prospects // Izvestiya Komi nauchnogo centra Uro RAN (in Rus.). 2012. No. 9. P. 46-54.

15. Nosko M.M., Pivnyuk V.M., Solyanik G.I., Kulik G.I., Todor I.N., Momot V.Ya., Melnikov O.R., Ponomareva O.V. Biodistribution analysis of cisplatin in liposomal form in animals with cisplatin-resistant and cisplatin-sensitive carcinoma // Exp Oncol. 2010. Vol. 32(1). P. 40-43.

16. Eka-Putra Gusti-Ngurah-Putu, Leaf Huang, YihChih Hsu. Effective Combined Photodynamic Therapy with Lipid Platinum Chloride Nanoparticles Therapies of Oral Squamous Carcinoma Tumor Inhibition// J Clin Med. 2019. Vol. 8(12). 2112. DOI: $10.3390 / \mathrm{jcm} 8122112$.

17. Monira M Rageh, Reem H El-Gebaly, Marwa M Afifi. Antitumor activity of silver nanoparticles in Ehrlich carcinomabearing mice. // Naunyn Schmiedebergs Arch Pharmacol. 2018. Vol. 391(12). P. 1421-1430. DOI: 10.1007/s00210-018-1558-5.

18. El-Naggar, N. E.-A., Hussein, M.H., \& El-Sawah, A.A. Phycobiliprotein-mediated synthesis of biogenic silver nanoparticles, characterization, in vitro and in vivo assessment of anticancer activities // Scientific Reports. 2018. Vol. 8(1). 8925. DOI: 10.1038/s41598-018-27276-6.

19. El Bialy B.E., Hamouda R.A., Khalifa K.S., Hamza H.A. Cytotoxic effect of biosynthesized silver nanoparticles on Ehrlich ascites tumor cells in mice // Int. J. Pharm. 2017. Vol.13. P.134-144. DOI: 10.3923/ijp.2017.134.144.

20. Goltsev A.N., Babenko N.N., Gaevskaya Yu.A., Bondarovich N.A., Ostankov B.V. and Chelombitko O.V. Application of nanoparticles based on rare earth orthovanadates elements to inactivate Ehrlich carcinoma growth // Biotechnologia Acta (In Ukraine). 2015. Vol. 2. No. 8(4). P. 113-121. DOI: 10.15407/ biotech8.04.113.

21. Krugly B.I., Nicholas E.D., Severin E.S., Barsegyan G.G., Yabbarov N.G., Tereshchenko O.G., Dunin O.A., Zenin V.A., and Tulaev A.I.. The comparative study of anti-tumor activity and safety of the novel protein-targeted actinomycin series on experimental tumor models in mice // Oncopediatrya (in Rus.). 2016. Vol. 3(3). P. 188-199. DOI: 10.15690/onco.v313.1597.

22. Ryabchenko A.V., Tverdokhleb N.V. and Knyazev R.A. Ehrlich ascitic carcinoma cells as a model for transfection in vitro // Fundamental'nye issledovaniya. (in Rus.). 2014. Vol. 5(6). P. 1213-1217.; URL: https://fundamental-research.ru/ en/article/view?id=34069. 
23. Sumenkova D.V., Knyazev R.A., Polyakov L.M. and Panin L.E. The role of macrophages in regulation of biosynthesis of proteins in cells of Ehrlich carcinoma // Siberian Journal of Oncology (in Rus.). 2010. Vol. 2(38). P. 30-34.

24. Deryagina V.P., Ryzhova N.I., Savluchinskaya L.A. Golubeva I.S. and Khochenkov D.A. Features of expression of NO-synthases (iNOS and eNOS) during of Ehrlich carcinoma growth depending on the grows rate // Vestnik Onkologicheskogo Centra (in Rus.) 2018. Vol.29(1-2). P. 40-44.; URL: ELibrary.RU https://elibrary.ru/item.asp?id=36433797.

25. Chen Y, Song Y, Du W, Gong L, Chang H, Zou Z. Tumor-associated macrophages: an accomplice in solid tumor progression // J Biomed Sci. 2019. Vol. 26(1). 78. DOI: 10.1186/ s12929-019-0568-z.

26. Chun-Qing Song, Da-Zhuang Sun, Yong-Min Xu Chen Yang, Quan Cai, Xue-Song Dong. Effect of endoplasmic reticulum calcium on paraquat-induced apoptosis of human lung type II alveolar epithelial A549 cells // Mol Med Rep. 2019. Vol. 20(3). P. 2419-2425. DOI: 10.3892/mmr.2019.10469.

27. Kondakova I.V., Kokurina G.V., Smirnova L.P. and Borunov E.V. Regulation of tumor cell proliferation and apoptosis by free radicals // Siberian Journal of Oncology (in Rus.). 2005. Vol. 1. P. 58-61.

28. Zamay, T.N., Zamay, A.S. Influence of ATP on Ehrlich ascites carcinoma cell free cytoplasmic calcium concentration in the course of tumor growth // Biochemistry (Moscow). 2006. Vol. 71. P. 1090-1095.

29. Pallichankandy S, Galadari S, Rahman A and Thayyullathil F. Reactive oxygen species and cancer paradox: To promote or to suppress // Free Radic Bio Med. 2017. Vol. 104. P.144-164. DOI: 10.1016/j.freeradbiomed.2017.01.004.

30. Tursunova N.V., Churin B.V. and Klinnikova N.G. Antitumor activity of compounds of natural origin // Modern Problems of Science and Education (in Rus.). 2018. Vol. 5; URL: https://science-education.ru/ru/article/view?id=28056. DOI: $10.17513 /$ spno.

31. Urazova L.N., Sultanov V.S., Kuznetsova T.I., Nechaev K.A., Roshchin V.I., Nikitina T.V. Anti-tumor activity of the drug Ropren. Polyprenols in Oncology // Development of scientific research and surveillance of infectious diseases: Proceedings of the International conference (St. Petersburg May 1820 2010). FSIS held them. Pasteur of Rospotrebnadzor (in Rus.). 2010. Vol. 148.; URL//https: //tayga8.com/science/.

32. Deryagina V.P., Ryzhova N.I., Razin A.N., Trukhanova L.S., Filippova I.A., Kiseleva T.V., Bocharova O.A. Experimental study of the effect of Lentinus edodes (Shiitake) on tumor growth in mice using models of transplantation and chemical carcinogenesis // Russian journal of Oncology No. 2009. Vol. 1. P. 33-38.

33. Marina Khatun, M Rowshanul Habib, M Ahasanur Rabbi, Ruhul Amin, M Farhadul Islam, M Nurujjaman, M Rezaul Karim, M Habibur Rahman. Antioxidant, cytotoxic and antineoplastic effects of Carissa Carandas Linn leaves // Exp Toxicol Pathol. 2017. Vol. 69(7). P. 469-476. DOI 10.1016/j.etp.2017.03.008.

34. Emdad Hossain, Saikat Chakroborty, Ahmed Milan, Pronobesh Chattopadhyay, Subhash C Mandal, J K Gupta. In Vitro and in Vivo antitumor activity of a methanol extract of Dregea Volubilis leaves with its antioxidan effect // Pharm Biol. 2012. Vol. 50(3). P. 338-343. DOI $10.3109 / 13880209.2011 .600320$

35. Indrajit Karmakar, Narayan Dolai, R B Suresh Kumar, Biswakanth Kar, Sudipendra Nath Roy, Pallab Kant Haldar. Antitumor activity and antioxidant property of Curcuma Caesia against Ehrlich's ascites carcinoma bearing mice// Pharm Biol. 2013. Vol. 51(6). P. 753-759. DOI: 10.3109/13880209.2013.764538.

36. Maram Hussein Zahra, Tarek A R Salem, Bishoy ElAarag, Nermeen Yosri, Samah El-Ghlban, Kholoud Zaki, Amel H Marei, Aida Abd El-Wahed, Aamer Saeed, Alfi Khatib, Mohamed F AlAjmi, Abdulrahman M Shathili, Jianbo Xiao, Shaden A M Khalifa, Hesham R El-Seedi Alpinia zerumbet (Pers.). Food and medicinal plant with potential in vitro and in vivo anti-cancer activities // Molecules. 2019. Vol. 24(13). 2495. DOI: $10.3390 /$ molecules24132495.

37. Jephesson Santos, Monalisa Brito, Rafael Ferreira, Ana Paula Moura, Tatyanna Sousa, Tatianne Batista, Vivi- anne Mangueira, Fagner Leite, Ryldene Cruz, Giciane Vieira, Bruno Lira, Petrônio Athayde-Filho, Helivaldo Souza, Normando Costa, Robson Veras, José Maria Barbosa-Filho, Hemerson Magalhães, Marianna Sobral. Th-biased immunomodulation and in vivo antitumor effect of a Novel Piperine Analogue // Int J Mol Sci. 2018. Vol. 19(9). 2594. DOI: 10.3390/ijms19092594.

38. Zueva E.P., Razina T.G., Amosova E.N., Krylova S.G., Lopatina K.A., Efimova L.A., Safonova E.A., Rybalkina O.Yu., Khotimchenko Yu.S. Influence of chitosans with different molecular weights on the development of Ehrlich adenocarcinoma and the effectiveness of cyclophosphane in mice// Tihookeanskij medicinskij zhurnal (In Russian).2010; Vol. 2. P. 82-84; URL: ELibrary.RU http://elibrary.ru/item.asp?id=16219931.

39. Razina TG, Zueva EP and Amosova EN. Influence of fucoidan from the marine brown algae Laminaria Japonica on the development of Ehrlich adenocarcinoma and Lewis carcinoma and effect cyclophosphan in mice. Tihookeanskij medicinskij zhurnal (in Rus.). 2010. Vol.2. P. 36-39; URL:ELibrary.RU http://elibrary.ru/item.asp?id=16219931.

40. Zlobnova N.V. and Krivoshapko O.N. Studying the anti-tumor activity of components polyphenol complex of seagrass Zostera Marina in vivo // Scientific almanac (in Rus.). 2015. Vol. 8(10). P. 1025-1027; URL: ELibrary.RU http://elibrary.ru/ item.asp?id=24277306 DOI: 10.17117/na. 20015.08.1025.

41. Alephirov A.N., Bespalov V.G., Stukov A.N., Murazov Ya.G., Semenov A.L., Krupskaya E.O. Anti-tumor activity of Aconitum Soongaricum tincture on the Ehrlich carcinoma model // Plant Resources (in Rus.). 2012. Vol. 3. P. 428-442; URL: http://www.travolekar.ru/arch/rr 2012 ehrlich.pdf.

42. Nariman K Badr El-Din, Said K Areida, Kvan O Ahmed, Mamdooh Ghoneum. Arabinoxylan rice bran (MGN3/Biobran) enhances radiotherapy in animals bearing Ehrlich ascites carcinoma // J Radiat Res. 2019. Vol. 60(6). P. 747-758. DOI: $10.1093 /$ jrr/rrz055.

43. Soo Liang OO, Debbie McMullen and Terry Golombick. Evidence-based review of BioBran/ MGN-3 Arabinoxylan compound as a complementary therapy for conventional cancer treatment // Integrative Cancer Therapy. 2017. Vol. 17 (2). P. $165-178$. DOI: $10.1177 / 1534735417735379$

44. Rostovtsev N.M., Pasternak A.E. and Kotlyarov N.A. Morphological changes in experimental tumors during photodynamic therapy // Pediatricheskij Vestnik Iuzhnogo Urala (in Rus.). 2015. Vol. 2. P. 46-49; URL: https://www.odkb74.ru/pdf/ pediatricheski vestneyk/Pediatricheski vestneyk Iuzhnogo Urala \%202015-2.pdf/87.

45. Ivanov A.A., Nasonova T.A., Darenskaya N.G., Dobrynina O.A. and Sidorovich G.I. Experimental model for the study of radiation suppression of antitumor resistance // Radiatsionnaia Biologiia, Radioecologiia, (in Rus.). 2009. Vol. 49(4). P. 449-455.

46. Balakin V.E., Shemyakov A.E., Zaichkina S.I., Rozanova O.M. Smirnova EN., Romanchenko S.P., Sorokina S.S., Strelnikova N.S. The remote effects of radiation after hypofractionated irradiation with protons of Ehrlich ascites carcinoma in mice // Biophysics (in Rus.). 2017. Vol. 62(1). P. 161-167.

47. Samsonova A.S., Filimonova M.V., Korneeva T.S., Shevchenko L.I., Filimonova A.S., Makarchuk V.M. Possibilities of using the NOS inhibitor as a means of preventing radiation damage to the skin // Advances in Molecular Oncology (in Rus.). 2018. Vol. 5 (4): P. 103.

48. Andrew B Gapeyev 1, Tatiana P Kulagina, Alexander V Aripovsky. Exposure of tumor-bearing mice to extremely high-frequency electromagnetic radiation modifies the composition of fatty acids in thymocytes and tumor tissue // Int J Radiat Biol. 2013. Vol. 89(8). P. 602-610. DOI: 10.3109/09553002.2013.784426.

49. Belsky Yu.P, Belskaya N.V., Danilets M.G., Trofimova E.S., Patrushev V.K., Agafonov V.I. Ehrlich tumor cells stimulate T- cells production of interferon -gamma and are resistant to autocrine nitric oxide // Voprosy Onкоlogii (in Rus.). 2004. Vol. 50(6). P. 689-692.

50. Snigereva A.V., Vrublevskaya V.V., Zhmurina M.A., Skarga Yu.Yu., Morenkov O.S. The mechanisms of stimulation of migration and invasion of tumor cells by extracellular heat shock protein 90 (eHsp 90) in vitro // Biophysics. (in Rus.). 2018. Vol. 63. P. 931-939. DOI: 10.1134/SOOO6302918060145. 